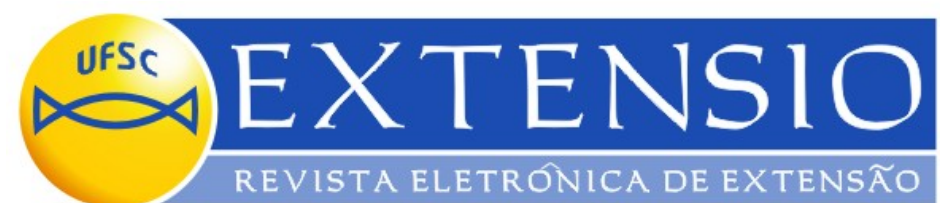

\title{
SERVIÇO DE ORIENTAÇÃO PROFISSIONAL DO LIOP - UFSC À COMUNIDADE: TRAÇANDO NOVOS CAMINHOS
}

\author{
Talissa Palma Muller e Juliana Scariot Schmidt \\ Acadêmicas do curso de Psicologia, UFSC \\ Dulce Helena Penna Soares
}

Professora Doutora do Departamento de Ciências da Psicologia, UFSC (Coordenadora) dulcepenna@terra.com.br

\section{Resumo}

Apresentam-se, neste artigo, aspectos relativos à experiência vivenciada durante as atividades realizadas em uma escola estadual, localizada no bairro Coqueiros em Florianópolis, desenvolvidas no decorrer de 2007, como projeto de extensão do Departamento de Psicologia, com o apoio do Departamento de Projetos de Extensão (DPE), da Universidade Federal de Santa Catarina (UFSC). Este projeto teve como intuito levar o trabalho de orientação profissional diretamente à comunidade.

Palavras-chave: Orientação profissional. Vestibular. Comunidade.

\section{PROFESSIONAL GUIDANCE FROM LIOP - UFSC TO COMMUNITY: TRACING NEW WAYS}

\begin{abstract}
This paper is about a Professional guidance that took place in a public state school, in Coqueiros, located in Florianópolis,during the year 2007, as a extension project from Psychology Departament with support of Extension Projects Departament from Universidade Federal de Santa Catarina (UFSC). This project had the purpose to offer professional guidance to community.
\end{abstract}

Keywords: Professional guidance. Entrance exam. Community. 


\section{Introdução}

O mercado de trabalho brasileiro sofreu consideráveis modificações nas últimas décadas. Um mapa de trabalho do Brasil produzido pelo IBGE (2001) registrou essas mudanças no período compreendido entre 1992 e 1997. Este mapa indica acréscimo de 1.324.975 brasileiros desocupados naquele período. Segundo a pesquisa, a taxa de ocupação (proporção das pessoas ocupadas na população economicamente ativa) é sempre menor nos grupos compreendidos entre quinze e vinte e quatro anos. O cenário brasileiro, assim, configura-se pela baixa perspectiva dos jovens de inserção no mundo de trabalho, entre todas as camadas sociais,

Soares (2002) enfatiza a escolha profissional como uma das primeiras dificuldades que o jovem enfrenta ao ingressar na classe trabalhadora. A autora ressalta vários fatores que intervêm nesta decisão, como a influência dos pais, do ambiente social e a pressão quanto ao fato de esta escolha implicar em assumir uma identidade profissional. De acordo com Soares (2002) o projeto profissional de cada pessoa é influenciado, desde a infância, pelas representações sociais positivas e negativas das profissões, principalmente aquelas exercidas por seus pais. Assim, assume-se aqui a posição de que o trabalho é parte integrante da vida das pessoas mesmo antes de exercerem qualquer atividade. Percebe-se que inúmeros são os fatores que podem interferir no sentido e no significado dado ao trabalho e, consequentemente, regular a dimensão desta atividade para cada pessoa, tornando-o mais ou menos importante em suas vidas.

Ao final do século XIX e início do século XX, em meio às transformações ocorridas nos modos de produção, surgiu a orientação profissional (OP). A OP originou-se, portanto, diretamente vinculada à Seleção e Orientação Profissional tendo como objetivos a adaptação do homem ao trabalho e, consequentemente, aumento na sua produtividade (MELO-SILVA e JACQUEMIN, 2001). Tais objetivos foram modificando-se com o passar dos anos. Para Soares-Lucchiari (1993), o objetivo da OP é a facilitação da escolha profissional. Facilitar a escolha significa participar do processo, auxiliando o orientando a pensar em suas dificuldades e ajudá-lo a trabalhá-las, para assim, ele próprio descobrir o caminho a seguir.

A adolescência é uma época marcada por mudanças, como implica a etimologia da palavra: adolescere, em latim, "crescer". A escolha profissional nessa fase é um momento repleto de dúvidas, autocobrança e insegurança. A orientação profissional tem como um dos seus objetivos auxiliar o orientando a melhor compreender esses sentimentos através de um processo de autoconhecimento somado a um trabalho de informação profissional e, por fim, a 
escolha propriamente dita. A última etapa não necessariamente precisa ser feita pelo orientando durante o processo de orientação, essa pode ocorrer posteriormente, mas alimentada pelo processo vivenciado pelo jovem.

A orientação profissional tem como finalidade a ampliação da consciência do indivíduo sobre a realidade, instrumentando-o para agir, no sentido de transformar e resolver as dificuldades que essa realidade lhe apresenta, possibilitando uma reflexão acerca dos aspectos psicológicos, econômicos e sociais que influenciam a escolha; discutir a relação homem-trabalho; informar sobre as profissões e possibilitar autoconhecimento relacionado à escolha. Justifica-se e ressalta-se, assim, a importância do trabalho de Orientação Profissional em escolas públicas, tendo em vista as desigualdades sócio-econômicas que o Brasil apresenta, trazendo para aquele contexto uma reflexão e possível mudança de tais condições.

Segundo Bastos (2005) entre a escolha profissional realizada e a sua efetivação, há vários fatores condicionantes que podem interferir na realização do curso ou da profissão desejada. Na escolha profissional do aluno do Ensino Médio público, há ainda mais elementos, como a necessidade de trabalhar, a falta de recursos para pagar um cursinho prévestibular ou uma faculdade, etc., que podem ter um peso decisivo na concretização de suas escolhas.

A Orientação Profissional tem ajudado mais a alunos de escolas particulares (que possuem diferentes possibilidades de escolha e maiores condições econômicas para escolherem estudar em faculdades privadas) do que aos de escolas públicas, pois, para esses, outros fatores ligados à sua condição de classe interferem em suas trajetórias educacionais e profissionais. É fundamental conhecer esses fatores para oferecer subsídios para que os orientadores repensem sua atuação no atendimento desses alunos, percebendo os limites da Orientação Profissional e enfrentando os desafios que são colocados a essa prática (BASTOS, 2005).

Segundo (BASTOS, 2005), a prática de OP nas escolas públicas poderia auxiliar os alunos a refletirem sobre seu futuro profissional, propiciando um espaço de discussão a respeito do trabalho, preparando o aluno para uma inserção consciente e crítica no mundo do trabalho. A ausência desse tipo de discussão dentro da escola pode fazer com que seus alunos saiam despreparados para a construção de estratégias que lhes permitam enfrentar criticamente as dificuldades e buscar novos caminhos na concretização de seus projetos de vida.

A ideia deste projeto nasceu da consideração da importância da OP nesse contexto e da demanda verificada no Serviço de Atendimento Psicológico da Universidade Federal de 
Santa Catarina, que em semestres anteriores, registrou um número de atendimentos superior a trezentas pessoas em orientação profissional e de cento e cinquenta pessoas em re-orientação profissional. Além de faltar infra-estrutura para um número maior de atendimentos na UFSC, pensa-se na dificuldade de locomoção dos jovens. Assim, considera-se importante atender o jovem em sua localidade, facilitando o seu envolvimento nesse processo.

A partir desta necessidade, considerou-se a possibilidade de estender as atividades do Laboratório de Informação e Orientação Profissional (LIOP) à comunidade. Assim, entrou-se em contato com a coordenadora da escola e fez-se o acordo. Para garantir o sigilo profissional e proteger a identidade dos alunos optou-se pela não revelação do nome da escola. Esta situase no bairro Coqueiros, Florianópolis, SC. Atende a educação infantil (pré-escola), ensino fundamental ( $1^{\mathrm{a}}$ a $8^{\mathrm{a}}$ série $)$ e ensino médio. São ministradas aulas nos três períodos: matutino, vespertino e noturno. Foram atendidos, por este projeto, cinquenta e dois alunos de três turmas de ensino Médio no período Vespertino $\left(1^{\circ}, 2^{\circ}\right.$ e $3^{\circ}$ ano).

$\mathrm{Na}$ experiência de mais de vinte anos na realização de OP na UFSC, comprovou-se que esta e a preparação psicológica antes da escolha profissional são necessárias, principalmente, para o jovem que está vivendo um período de instabilidade neste momento e precisa de apoio. Bastos (2005), ainda afirma que a escolha profissional dos entrevistados, que não haviam passado por orientação, mostrou-se drasticamente restrita e determinada por estereótipos das profissões. A impossibilidade de participar de um programa de OP que lhes desse oportunidade de discutir a questão da inserção produtiva numa sociedade capitalista restringiu as chances de analisar mais criticamente suas "escolhas" profissionais.

Também é importante ressaltar que a escolha consciente possibilita uma decisão mais segura e que cada escolha feita faz parte de um projeto de vida que se realiza, assim, diminuem-se as chances de desistências de curso, e aumenta-se a probabilidade de formar um profissional mais competente e motivado a exercer sua profissão. Com este projeto, visou-se, também, uma aproximação dos conceitos teóricos aprendidos na universidade, por parte das estagiárias, com a realidade prática da profissão.

\section{Material e métodos}

Durante o último semestre de 2007, foram realizados encontros com turmas do $1^{\circ}, 2^{\circ} \mathrm{e}$ $3^{\circ}$ ano do segundo grau da Escola Estadual de Ensino Básico Presidente Roosevelt. As técnicas utilizadas em cada etapa do processo de orientação profissional (selecionadas em função das características peculiares de cada grupo) foram retiradas de Soares (2002, p. 342- 
356). A metodologia descrita por Soares (2002), e prevista no projeto inicial, foi adaptada em virtude das limitações apresentadas por trabalhar-se em colégio público, pois o tempo reservado para a orientação foi no momento de aula.

Optou-se por realizar seis encontros com a turma de $1^{\mathrm{o}}$ ano do segundo grau, cinco encontros com a turma de $2^{\circ}$ ano do segundo grau e seis encontros com a turma de $3^{\circ}$ ano do segundo grau. O tempo médio de cada encontro foi de uma hora e meia. A primeira atividade realizada nas três turmas foi uma técnica de apresentação, para que os alunos se familiarizassem com as orientadoras e essas com eles e a aplicação de um questionário (ANEXO A e B) para levantamento de interesses e necessidades. O questionário continha uma breve explicação do material, um cabeçalho para dados pessoais e 17 perguntas sobre preferências, orientação profissional, vida escolar e família.

A partir da análise do primeiro contato com as turmas e dos questionários, as orientadoras avaliaram os planos de atividade específicos para cada turma. O enfoque na turma de $1^{\circ}$ ano foi dado à etapa que proporcionava informação profissional, no $2^{\circ}$ ano foram realizadas as três etapas (autoconhecimento, conhecimento do "mundo" das profissões e a escolha profissional) e na turma do $3^{\circ}$ ano buscou-se enfatizar a etapa de autoconhecimento. Os materiais utilizados nas atividades foram: papel A4, canetinha, lápis de cor, caneta esferográfica, giz de cera, (materiais, ora fornecidos pelas orientadoras, ora pelo LIOP) e jogos lúdicos e informativos proporcionados pelo Laboratório de Orientação e Informação Profissional. (ANEXOS C, D e E)

\section{Resultados e análises}

A metodologia descrita no projeto inicial era a realização de grupos com oito a doze participantes. Seriam realizados oito encontros de duas a três horas com cada grupo. Os participantes, de diferentes faixas etárias, seriam agrupados de acordo com o horário disponível de cada um. Ao conversar com a orientadora pedagógica do colégio, verificou-se que o interesse da direção da escola era disponibilizar tempo para os grupos de OP durante o período letivo regular e que as orientadoras assumissem em horário de aula a turma inteira. Assim, só puderam ser realizados cerca de seis encontros com cada turma, que tinha em média 15 alunos e o tempo foi em média de uma hora e meia (tempo de duas aulas faixas). Considera-se que o ideal seria realizar os encontros com número menor de adolescentes, porém, em virtude da necessidade do colégio e dos alunos, teve-se que adaptar o método. 
O interesse inicial do projeto era que os encontros fossem feitos em salas adaptadas ao trabalho em grupo, de forma confortável e acolhedora. A escola possuía tal espaço, mas ele estava vazio e como o material pedido à FAPEU (almofadas, entre outros materiais) só chegou ao final da realização do projeto, os encontros tiveram que ser realizados na mesma sala em que os orientandos tinham aula. Acredita-se que a falta de tal espaço, algumas vezes prejudicou o trabalho em virtude de que muitas vezes era necessário mudar as carteiras de lugar para que pudessem ser realizadas as atividades, o que fazia barulho e agitava os alunos; em outros momentos, o local não proporcionava espaço suficiente para a realização adequada das tarefas que precisaram ser adaptadas.

No princípio, o planejamento por encontro era muito semelhante para as três turmas, mas ao deparar-se com a realidade social, os diferentes projetos de futuro, a escassez de tempo em sala e, principalmente, pela necessidade de cada turma, expressa no questionário, e no decorrer de cada dia de atividade, teve-se que remanejar as atividades. Segundo SoaresLucchiari (1993), o desenrolar dos grupos é específico e o planejamento deve ser alterado conforme as necessidades surjam ao longo do processo.

Bastos (2005) verificou que a questão do desemprego também fez com que alguns entrevistados não considerassem fundamental a realização de um curso superior, pois muitos profissionais graduados estão sem emprego. Tais questionamentos também foram apresentados nas turmas aqui relatadas. Alguns dos alunos não pretendiam fazer vestibular, pois tinham planos alternativos de profissionalização.

Para Coutinho (2006), temáticas como reestruturação produtiva, relações de trabalho, competitividade e desemprego são objetos de reflexão ao discutir-se a centralidade, os sentidos e o significado que o trabalho assume no modo de vida contemporâneo. Se antes tínhamos estabilidade, progressões de carreira, envelhecimento dentro de uma mesma empresa, nos últimos tempos, com o fortalecimento do capitalismo e as mudanças no modo de produção surgiram novos paradigmas: tem-se instabilidade e insegurança e exige-se flexibilidade dentro das atividades exercidas. Considerando o papel central que o trabalho ocupa em nossa sociedade e relacionando-o com o modo de viver contemporâneo (repleto de transformações constantes, permeado pela cultura do descartável e a quantidade de novas informações que circulam), tem-se como algumas das consequências uma mudança nas formas de trabalho, um novo perfil de trabalhador e uma grande diferença na concepção de "futuro" e elaborações de projeto dos jovens.

Alguns discursos disseminados ideologicamente pela mídia e pela sociedade fazem com que ter sucesso econômico, reconhecimento social de status e poder passem a ser vistos 
como objetivo principal da profissão. Tais temas foram centrais em discussões, principalmente com a turma do terceiro ano, em que a escolha pela profissão era mais urgente e mais presente no seu dia-a-dia, pois os alunos desta série mostraram-se mais preocupados com questões mais emergentes, como por exemplo, o sustento próprio e da família.

$\mathrm{O}$ estilo de vida competitivo faz com que o indivíduo traga para sua vivência a ansiedade que está ligada à necessidade de sucesso financeiro, como também às incertezas e instabilidade que a nova economia impõe. Como disse Marques (2007), em oposição à estabilidade existente no passado, os valores de nossa época são de constantes mudanças. Tais alterações no modo de vida das pessoas tornam estas questões centrais da discussão acerca dos projetos de futuro dos jovens de classe popular.

O que o presente artigo relata vem ao encontro do que Marques (2007) escreve em seu trabalho sobre os sentidos que estudantes do primeiro ano de graduação elaboram sobre seus projetos de futuro. O referencial teórico utilizado pela autora foi a psicologia sócio histórica. O mesmo autor afirma que, para os jovens, o futuro profissional caracteriza-se por um "sei lá", um não pensar, não refletir, não elaborar planos/projetos. Este "não pensar sobre", vem atrelado a significações sociais de "ganhar dinheiro agora" quase que numa incapacidade de se ver no futuro, evidenciando assim uma falta de motivação para seguir adiante. Tal falta de motivação foi corroborada pelos professores do colégio em questão, que ao serem indagados sobre o interesse dos alunos nas atividades escolares, afirmavam ver em grande maioria dos estudantes uma falta de empenho nas disciplinas por não verem futuro ali.

\section{Turma do primeiro ano do ensino médio}

Foram atendidos dezenove jovens, entre eles, oito meninos e onze meninas, com idade média de quinze anos; o mais novo com quatorze e o mais velho dezoito. Sobre a ocupação dos pais dos alunos, duas mães e um pai foram declarados com curso superior e os demais são profissionais sem capacitação técnica ou curso superior. As expectativas dos alunos em relação à orientação profissional eram "tirar dúvidas, aprender bastante, receber ajuda, fazer com que escolhessem a melhor oportunidade, dar ideia do que fazer no futuro, saber mais o que queriam e que isso poderia ajudar no futuro". Quando questionados sobre interesse e possíveis opções para o vestibular, dez alunos disseram ter interesse no ensino superior, mas ficaram em dúvida quanto à escolha do curso; duas pessoas mencionaram a vontade de fazer curso técnico, quatro disseram não ter interesse no vestibular e três pessoas deixaram em branco. 
Esta turma mostrou se adaptar melhor às atividades mais dinâmicas e que tinha pouco conhecimento acerca do mundo das profissões, logo as orientadoras programaram várias atividades de informação profissional através de jogos e atividades lúdicas.

\section{Turma do segundo ano do ensino médio}

A turma do segundo ano do ensino médio era composta por dezenove alunos, a idade média da turma era de dezesseis anos; sendo que o mais novo tinha quinze anos e o mais velho dezoito. Havia treze meninas e seis meninos em sala. Eles sabiam pouco sobre a OP no início do trabalho, mas tinham expectativa de que a orientação profissional os auxiliasse na escolha de uma profissão.

Entre os pais dos alunos desta turma, três possuem curso superior ou técnico, os demais são profissionais sem capacitação técnica ou curso superior. Três orientandos citaram apenas o pai como base de sustento da família e seis citaram apenas a profissão da mãe, um orientando, além de citar a profissão dos pais, citou a profissão da avó.

Ao responder sobre o interesse em fazer vestibular, dezoito alunos responderam ter interesse em fazer vestibular, apenas um não respondeu essa questão e nenhum dos orientandos mostrou interesse em realizar a prova do vestibular. Dos alunos que responderam ter interesse em fazer vestibular, dez mostraram-se mais decididos sobre qual curso e seus motivos, e outros oito tinham ideias conflitantes em relações aos cursos pretendidos.

Esta era uma turma calma, que demonstrou maior questionamento sobre o futuro profissional e se mostrou preparada para que fossem trabalhadas as três etapas do processo de orientação. Foram feitas atividades que proporcionassem o conhecimento de si, do mundo das profissões e o início do processo da escolha, propriamente dita, através de jogos e discussões.

\section{Turma do terceiro ano do ensino médio}

Foram atendidos quatorze jovens, entre eles, oito meninos e seis meninas, com idade média de dezessete anos; sendo o mais novo com dezesseis e o mais velho com vinte. Dos vinte e sete pais mencionados, foram declarados cinco com curso superior e os demais são profissionais liberais e prestadores de serviço como segurança, vidraceiro e porteiro. Das quatorze mães citadas, sete trabalham no lar. Sobre as expectativas dos alunos em relação à orientação profissional, a maioria disse não saber ou não ter nenhuma; um falou sobre a importância de receber ajuda e cinco deixaram a questão em branco. Em relação ao interesse e possíveis opções para o vestibular, nove disseram ter interesse no ensino superior, destes, 
quatro têm mais certeza quanto à escolha do curso, quatro pessoas mencionaram a vontade de fazer curso técnico e uma disse não ter interesse no vestibular. Como esta turma não tinha planos de realizar o vestibular em 2007, optou-se por discutir a realidade do mundo do trabalho, pois quando decidissem realmente fazer a prova estariam mais informados e conscientes das possibilidades acerca dos cursos, e também foram realizadas atividades que proporcionassem mais conhecimento sobre seus interesses.

Em sua pesquisa sobre estudantes de escolas públicas, Bastos (2005) questionou sobre a preparação para o vestibular oferecida pela escola, a maioria dos entrevistados considerou que a escola não ofereceu preparação, alegando principalmente a baixa qualidade do ensino público. Em depoimento, um dos entrevistados alegou que não havia feito vestibular por achar necessário um cursinho preparatório pelo qual não tinha condições de pagar. Essa alegação foi semelhante àquela feita por estudantes da turma do terceiro ano afirmando que não haviam se inscrito na prova do vestibular aquele ano, pois consideravam necessário um ano de cursinho para realmente se preparem para o vestibular, porém a maioria deles pretendia fazer no próximo ano tais aulas de preparação.

\section{Avaliação do processo de Orientação Profissional}

No último dia de atividades com cada turma, foi pedido que eles respondessem, anonimamente, algumas questões avaliativas (ANEXO F) do processo de orientação profissional, contando um pouco sobre como se sentiram durante os encontros e do que gostaram ou não gostaram em cada encontro. As respostas, em geral, mostraram que o objetivo em cada turma foi atingido.

Na turma do primeiro ano, muitas das respostas foram relacionadas com envolvimento afetivo entre eles e deles com as orientadoras, falavam de maior aproximação entre os alunos. Fato esperado em virtude de terem sido feitas muitas atividades em grupo nas quais eles deveriam se unir para terminar e vencer cada atividade ou competição.

As avaliações escritas pela turma do segundo ano mostraram que muitos conseguiram esclarecer suas dúvidas sobre o mundo das profissões e que se tornaram mais conscientes sobre a escolha da profissão. Foram retirados alguns trechos das avaliações que corroboram com tal constatação: "As dinâmicas foram bem preparadas e divertidas, me fizeram conhecer um pouco de cada profissão...”; “... aprendemos informações úteis e valiosas, futuramente irão nos ajudar muito... através deste projeto pensei em diversos cursos e possibilidades, com a orientação achei um curso que se identifica comigo e também me satisfaz, acredito que sem 
este projeto não acharia nenhum tipo de faculdade, assim me sinto mais preparado e confiante.”; “... me senti meio intimidado pois eram atividades que eu nunca tinha feito, mas gostei porque com aparentes brincadeiras nós aprendemos muito."

No terceiro ano, o tema central das avaliações foi a sensação de livre expressão de seus pensamentos: "Senti-me bem, livre, sem restrições, ou seja, liberdade de opinião... As aulas foram boas, bem explicativas, com debates e liberdade de opinião..."; "Gostei dos debates, pois a nossa turma não teve muitas oportunidades de fazer um debate.". Os debates foram considerados muito positivos pelas orientadoras, visto que seus objetivos era criar espaços para a auto-investigação e questionamentos sobre o futuro e que o trabalho em grupo pudesse proporcionar a ajuda mútua, ou seja, buscar nos colegas compreensão sobre seus medos e inseguranças.

\section{Considerações finais}

A experiência de fazer Orientação Profissional em uma escola pública de Florianópolis, aprendendo a ajustar o ideal com o real, foi muito enriquecedora para as orientadoras. Foi possível aprender não apenas em relação à Orientação Profissional, mas também em relação à coordenação de grupo e etapas de desenvolvimento.

Por trabalhar com três grupos que se mostraram bem diferentes entre si, e por lidarmos com uma turma, ou seja, um grupo já formado, houve vantagens e desvantagens durante o processo. Se, por um lado, já havia confiança entre os membros, por outro, questões de dificuldade na dinâmica do grupo, como por exemplo, brigas entre membros e rótulos préestabelecidos geravam diariamente desafios para as orientadoras. Estes serviram como estímulo e proporcionaram uma excelente oportunidade de aprendizagem, que não poderia ter sido experimentada se fosse trabalhado com grupos recém formados, como o previsto no projeto inicial.

Havia necessidade de mais tempo de atividades com os alunos para que fossem discutidas questões práticas sobre a universidade e o vestibular como, por exemplo, o formato da prova, como se resolvem as questões somatórias, as abertas, o que são as cotas, como se comportar durante a prova, como preencher o formulário de inscrição e quem ganha isenção.

Pôde-se perceber uma constante relutância em pensar sobre o futuro, mas que no decorrer do processo foi diminuindo. Após uma das primeiras atividades realizadas, um aluno do terceiro ano relatou a dificuldade de pensar sobre o futuro, mas ressaltou a importância 
dessas atividades, pois não estavam acostumados a pensar sobre ele. Um relato de um dos alunos demonstra tal fato: "Parei para refletir e pensei um pouco no futuro...".

$\mathrm{Na}$ pesquisa de Bastos (2005), nenhuma das escolas pesquisadas ofereceu algum tipo de Orientação Profissional (OP), o que se considera uma falha grave, pois como afirma Bock (2002), para os indivíduos das classes populares, há possibilidade de intervenção sobre sua trajetória; portanto não há determinação social absoluta e na perspectiva sócio-histórica, não se reconhece como meramente ideológica a possibilidade de escolha das classes subalternas, ao contrário, entende-se que nisso reside a possibilidade de mudança, de alteração histórica, ao reconhecer que os indivíduos podem, de certo modo, intervir sobre as condições sociais, por meio de ações pessoais ou coletivas, e a OP oferece ferramentas necessárias para tais alterações.

É evidente a importância da continuação de trabalhos desse tipo em relação à comunidade, pois se pode perceber que há uma crescente demanda por esse tipo de atividade em escolas públicas. A fala de um dos orientandos ressalta a importância desse tipo de trabalho: "Continuem com esses projetos, pois é com essas atitudes que o Brasil poderá ser modificado...".

Durante o trabalho nessa escola, professores que davam aula em outras localidades informaram o interesse dessas entidades de ensino no mesmo tipo de trabalho. Assim, reafirma-se a necessidade de instituir espaços específicos de suporte como o LIOP nas escolas para que os jovens possam efetuar reflexões críticas acerca dos seus projetos profissionais e, consequentemente, de vida.

Segundo Marques (2007) acompanhar os jovens nessa etapa, nessa construção de seu futuro é também proporcionar-lhes bem estar, diminuir probabilidades de doenças psicossomáticas, menor índice de evasão universitária, ocorrência de burn out precoce. Assim, a implantação de centros de atendimento ao aluno e as disciplinas de orientação ocuparão um espaço importante para lidar com a ambiguidade dos jovens frente ao futuro, ora incrédulos, ora iludidos, vivem em desafio constante.

Acredita-se que em uma próxima oportunidade, devido a essa aprendizagem, muitos dos problemas enfrentados nesse trabalho possam ser facilmente superados em virtude da experiência que ele proporcionou. 


\section{Referências}

BASTOS, J. C. Efetivação de Escolhas Profissionais de Jovens Oriundos do Ensino Público: Um Olhar sobre suas Trajetórias. Revista Brasileira de Orientação Profissional, 2005, 6 (2), pp. $31-43$

BOCK, S. D. Orientação Profissional: A Abordagem Sócio-Histórica. São Paulo: Cortez, 2002.

COUTINHO, M.C.; GOMES, J.S. Sentidos do trabalho: Reflexões a partir de uma oficina vivencial desenvolvida com jovens. Pesquisas e práticas psicossociais, v.1, n.1, São João Del Rei, jun, 2006.

IBGE. Mapa do mercado de trabalho do brasil. Rio de Janeiro: 2001. Disponível em: $<$ http://www.ibge.gov.br/home/estatistica/populacao/mapa_mercadotrabalho/mapa_mercado_ trabalho.pdf $>$ Acesso em: 20 jan. 2008.

MARQUES, F.M. Os sentidos que os estudantes do primeiro ano de graduação de administração da PUC-SP atribuem ao seu projeto de futuro profissional.In.: ENCONTRO NACIONAL DA ABRAPSO, 4., 2007, Rio de Janeiro. Anais.... Rio de Janeiro: UERJ, 2007.

MELO-SILVA, L.L. \& JACQUEMIN, A. Intervenção em Orientação Vocacional / Profissional: Avaliando resultados e processos. São Paulo:Vetor, 2001.

SOARES-LUCCHIARI, D.H.P.S. Pensando e vivendo a orientação profissional. São Paulo: Summus, 1993

SOARES,D.H.P. A escolha profissional do jovem ao adulto. São Paulo: Summus, 2002. $196 p$ 
EXTENSIO: Revista Eletrônica de Extensão

Ano $6 \cdot$ n. 7 • Julho de 2009 • ISSN: 1807-0221

\title{
ANEXO A
}

\author{
UNIVERSIDADE FEDERAL DE SANTA CATARINA \\ CENTRO DE FILOSOFIA E CIÊNCIAS HUMANAS \\ DEPARTAMENTE DE PSICOLOGIA
}

LABORATÓRIO DE INFORMAÇÃO E ORIENTAÇÃO PROFISSIONAL

Este questionário tem como objetivo conhecer um pouco melhor cada um, para auxiliar no processo de Orientação Profissional! Devido ao número de pessoas e o tempo disponível, não é possível fazer uma conversa mais direta com vocês! Sejam sinceros e tenham certeza que as informações aqui relatadas serão de acesso exclusivo a nós, estagiárias. Caso não se sintam confortáveis em responder alguma das perguntas, não há necessidade.

Com carinho,

Juliana e Talissa

*Nome

Idade:

Sexo: () F ( $(x) \mathrm{M}$

*Turma: 36

E-mail pessoal para contato:

* campo obrigatório

1) O que você sabe sobre a orientação profissional? Conhece alguém que já fez? acho que é uMa rientacia para nós sabermos en que vasuos trabalhar Nan conhege visguen que Ja fez iss.

2) Quais as expectativas sobre o que vai acontecer? O que imagina da O. P.? NCío sei

1) Como foi sua vida escolar? Onde estudou?

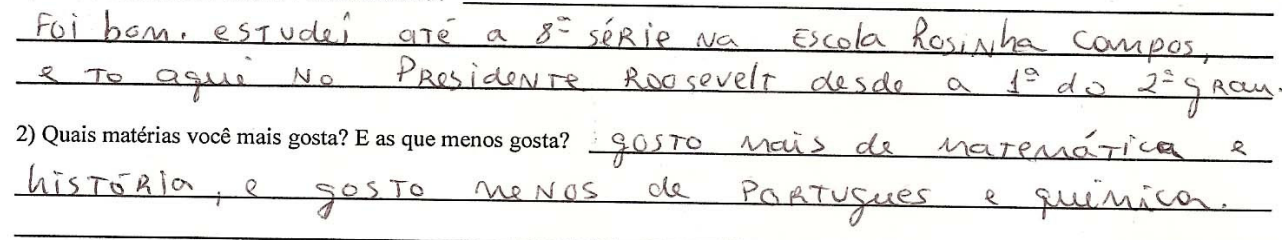

3) Teve algum fato marcante na sua trajetória escolar ou em sua vida que você gostaria de colocar? nao 


\section{ANEXO B}

4) O que yocê faz no seu tempo livre? Quais são suas atividades de lazer? eSCUTAR Músícon e Saik.

5) Quais cursos vocêjá pensou em fazer? inglês, e ma is al zuma co isa, Nä́ sei.

6) Qual a profissão de seus pais ou responsáveis? Eles exercem a profissão? Onde trabalham?

Pai - vitraceiro Orasmerese TRabalha Numa industria de vidros. máe - Servicos gerais numa academia

7) Você acha que eles fazem o que gostam? Explique. nî wha māe Nõó, men pai sm porgue é isso que ele faz hà mais de 20 avos e é ben sucedido vo que faz.

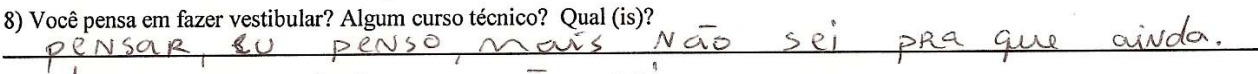
talvez arquitetura, ná̃ sei

9) Quais as expectativas de seus pais frente ao seu vestibular? eles geveren que en fa ca fincil do ano.

10) Você tem irmãos? sin, 3 in $\mathrm{s}$ às.

11) Qual(ais) profissão(ões) ou curso(s) que ele(s) exerce(m)? so' a mais velha trabatha. vuma Lan House.

12) E o(a) namorado(a)? Qual sua profissão ou o que pretende fazer ou faz? Náo tewho

13) E você, trabalha? Se sim, com quem e onde?

$$
\text { Nä́ }
$$

14) Sobre o Vestibular, quais as tuas expectativas? $\mathrm{E}$ os temores? Ná̃ sei, aivda to con muira auvida sobre o que fazer tevho medo de fazer a opcío errada

15) Responda rápido, se o vestibular fosse amanhã qual curso você faria? E por quê? 15) Responda rápido, se o vestibular fosse amanhã qual curso você faria? E por quê?
Näo sei, to peNsavdo Nisso faz tempo, é dificil
decidir agora de una hoka para outra.

\section{ANEXO C}




$$
\text { gosso e faco }
$$

ma morar

ir ao shopjing

comprar rolypas.

calcades

sair p/ baladas

sair de carro e molo

comer chocolate

- ir ao cimema

oriajar

ur a praia e parck -

Năo gosto e faco

assistrer as anlas de Port

Limpar a casa

T Mabalmar

aturar pessoas chatas

fazer Éalcaçai Fisica

responder meus pais

brigar com minhas

ermás

Fazer espertes

estidar pl prova

dever de casor

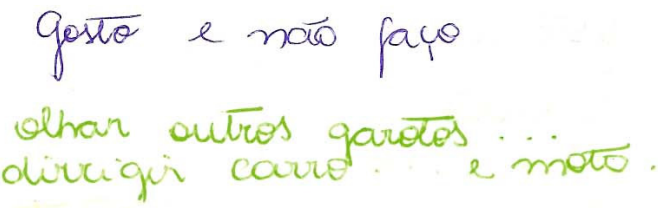

fazer uma tatuagem

dancar funk

usar savo curtar e

shouts

Ficar mo PC até tanal
Nä́o gosto e ri faco

Secar loupa

brigar ma rua

por yeiraing na lisgua pebor

ANEXO D 


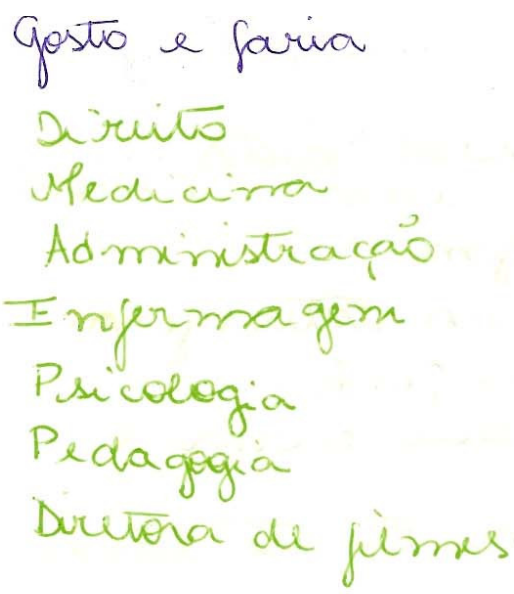

$$
\begin{aligned}
& \text { Gosto e nä́ parua } \\
& \text { Veterinaria } \\
& \text { Publicidade } \\
& \text { Hoda }
\end{aligned}
$$

Nä́ gosto e farra pastromimia arquituturo Ungentarice.
Nao gosto e ñ faria professera de adolexcente

ANEXO E 
EXTENSIO: Revista Eletrônica de Extensão

Ano $6 \cdot n$. 7 • Julho de 2009 • ISSN: 1807-0221

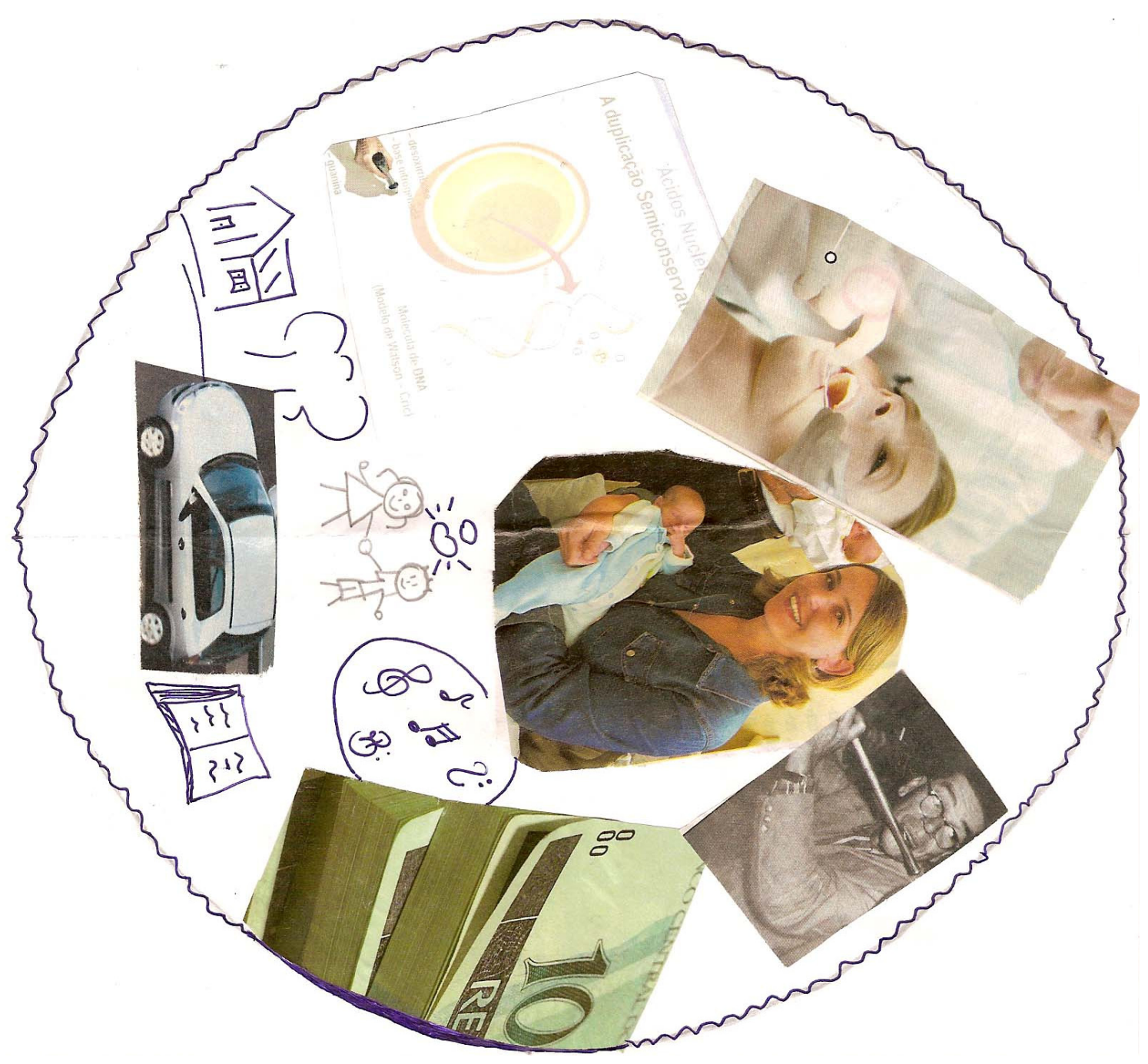

ANEXO F 
- Foram atividades dexcentraidas, engravado, porém mo

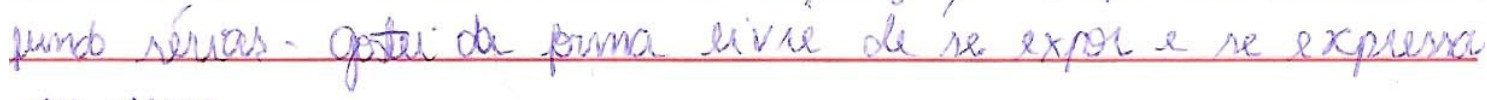
am goupo

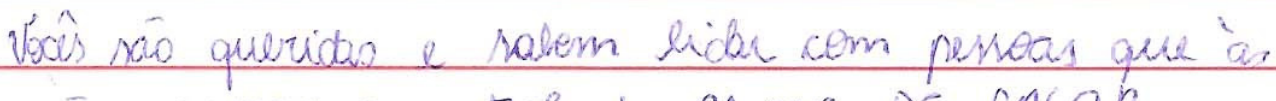

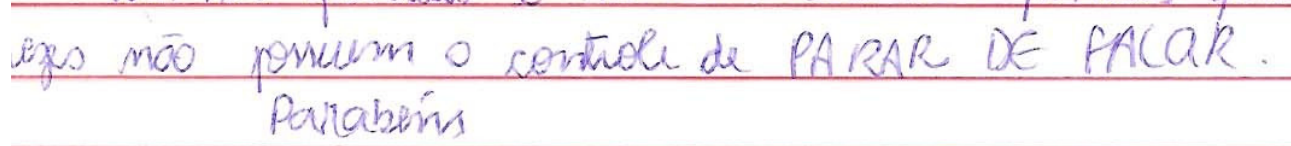

H 